\title{
El museo que queremos
}

\author{
M. Osuna Ruiz \\ Director del Museo de Huelva \\ J. Bedia García \\ Conservadora del Museo de Huelva \\ José $\mathrm{M}^{\mathrm{a}}$ Cuenca López \\ Profesor del área de Didáctica de las Ciencias \\ Sociales, Universidad de Huelva. Grupo DESYM \\ J. A. Asuero Mantero \\ Arquitecto redactor del "Proyecto básico de \\ remodelación y ampliación del Museo de Huelva
}

\section{Resumen}

La necesaria adecuación a la normativa vigente del edificio que alberga al museo de Huelva, sin duda proporcionará mejoras en la propuesta museológica de la institución y su consecuente adecuación museográfica. Los museos han de tender en la actualidad hacia la identificación ciudadana de patrimonio conservado en ellos, mediante su adecuada contextualización y el fomento del intercambio intelectual entre científicos y artistas con el público, a través de una oferta cultural didáctica y diversificadora tendente a lograr el tan deseado cambio de actitud frente al patrimonio.

\section{Palabras clave}

Huelva / Comunicación / Identificación / Investigación / Protección / Contextualización / Intercambio /Oferta didáctica / Aprendizaje / Cambios de actitud / Diversificación

\section{Justificación}

Con su incorporación en 1997 a la dirección del museo de Huelva, Manuel Osuna Ruiz recibe de la Delegación Provincial de Cultura el encargo de tra- bajar sobre el proyecto de remodelación de la Institución. El primer paso para establecer esta propuesta fue el acopio documental sobre los avances científicos producidos a lo largo de los últimos años en la provincia, tanto en arqueología como en las artes plásticas, resultando transcendental el análisis conceptual de la producción artística onubense a lo largo del siglo XX y la revisión de las teorías sobre la estructura y distribución del poblamiento humano del territorio en los distintos periodos históricos.

Una vez digerida la voluminosa documentación ', el segundo paso consistió en acotar y estructurar los diferentes contenidos a través de los cuales queríamos narrar la "Historia" de la actual provincia de Huelva. Y, al igual que ocurre en toda narración, decidir el inicio, definir su desarrollo y buscar un final acorde con el mensaje que se pretendía promover, evidenciando nuestro posicionamiento, en el que resulta decisivo asumir que junto a las tradicionales misiones de conservar, investigar y exhibir las colecciones, la divulgación y la comunicación desde perspectivas didácticas son cometidos esenciales del museo actual. En definitiva, asumir que la tarea de los museos no es otra que hacer significativa la Historia, llevando al público visitante los conocimientos científicos de tal forma que sea capaz de interpretarlos por sí mismo, al tiempo que se posibilita el disfrute de las colecciones en un ambiente de ocio y a través de un lenguaje específico favorecedor de una comunicación activa con los objetos.

Es obvio que para alcanzar estos objetivos resulta del todo imprescindible la desacralización de las piezas, la desmitificación de la arqueología y la humanización de las Bellas Artes, ya que los objetos que constituyen las colecciones y justifican la existencia misma de los museos han sido realizados, recogidos y considerados referentes culturales por seres de carne y hueso, con una intencionalidad de uso y disfrute similar a la que establecemos en la actualidad con lo que hoy nos rodea ${ }^{2}$. En definitiva, si un museo no se integra en el medio en el que desarrolla su actividad, si no consigue que los ciudadanos se identifiquen con su patrimonio y su propia Historia, es un museo muerto. Es por ello 
que trabajamos para que, tras su remodelación, el museo de Huelva constituya un referente esencial para el ciudadano onubense del siglo $X X \mid$ y para sus visitantes, un espacio temporal y una necesidad cultural en donde nos situamos todos ${ }^{3}$.

\section{El edificio, su entorno urbano y las colecciones}

Conocido por la mayoría, el edificio que actualmente alberga el Museo de Huelva queda situado en una de las avenidas más emblemáticas de la ciudad, la Alameda Sundheim, configurada como paseo y zona residencial de la burguesía colonial asentada en la ciudad en el último cuarto del siglo XIX y nexo actual entre el casco antiguo y el núcleo de mayor densidad poblacional de la ciudad. Su patronímico nos adentra en la especificación del modo de ser del onubense y su incansable búsqueda de una identidad autónoma y auténtica, oculta bajo la sensación de deber al "extranjero" todo lo nuevo y moderno. Es quizá ésta una de las razones que pesaron en el onubense Florentino Pérez Embid, Director General de Bellas Artes en los años setenta y afanado promotor del actual museo, para no impulsar la rehabilitación de alguno de los edificios de ambiente inglés como sede de la Institución, tal y como ocurriera en otras ciudades ${ }^{4}$. En efecto, mientras que la hoy emblemática Casa Colón era objeto de graves expolios debido a su abandono, se decide la construcción de un nuevo edificio en, entonces, una "tierra de nadie" con escasos atractivos para conceder a la joven sociedad onubense el acceso a su aprehensión simbólico identificativa ${ }^{5}$.

Los $3000 \mathrm{~m}^{2}$ con los que cuenta actualmente el edificio se hallan repartidos en tres plantas y un semisótano y, al igual que ocurre con otros de su misma categoría, su contenido se distribuye en las tres clásicas secciones (Arqueología, Bellas Artes y Etnología). La Sección de Arqueología ocupa en estos momentos $920 \mathrm{~m}^{2}$ y, sin duda, representa el elemento más significativo del museo tanto por la importancia de su colección como por el número de visitantes que atrae. Destacan por su calidad estética e importancia científica los objetos pertenecientes a las culturas megalítica, tartésica y romana, seguidos de una incipiente y cada vez más importante colección medieval islámica, consecuencia de los avances científicos alcanzados en este periodo.

La Sección de Bellas Artes cuenta actualmente con $650 \mathrm{~m}^{2}$ de exposición y un exiguo fondo con escasa estructuración, donde se destaca la colección de obras de Daniel Vázquez Díaz -constituida por depósitos del MNCARS, la Consejería de Cultura de la Junta de Andalucía y el Museo de Bellas Artes de Sevilla-, y un pequeño lote de obras contemporáneas de artistas locales que, pese a su dispersión y graves lagunas, presenta cierto interés. Una decidida apuesta por el arte local ha permitido que en los últimos tres años haya aumentado en número la sección mediante donaciones ${ }^{6}$, compras $^{7}$ y depósitos de obras de los artistas onubenses más destacados ${ }^{8}$. Por otro lado, el acuerdo alcanzado con la Diputación para establecer un taller de grabadores en el museo está dando lugar a la formación de una por ahora pequeña pero interesante colección de obra gráfica, tanto de artistas locales como de los invitados a impartir los ciclos formativos y de experimentación. El acierto de la propuesta ha significado así mismo, la complicidad de otros artistas grabadores ya consolidados, proponiendo donaciones y/o depósitos de sus obras; este es el caso de Granado Valdés, con un depósito de 25 obras pendiente de confirmación, o de Diego de Giráldez cuya obra se halla en similar situación.

En cuanto a la Sección de Etnología, son bien conocidos los acontecimientos que rodearon el abortado intento de crear un museo de esta especialidad en la localidad serrana de Aracena como sección del Museo de Huelva 9 . Herencia de esta circunstancia es la inexistencia, todavía hoy, de una propuesta acorde con la calidad y riqueza etnográfica que contempla la provincia. Mientras llega la ocasión, el museo promueve exposiciones de carácter temporal que favorecen el entendimiento, conservación y difusión del rico patrimonio cultural de nuestra provincia, al tiempo que apoya nuevas iniciativas surgidas al amparo de la acción municipal 10.

\section{La nueva propuesta y sus espacios museológicos}

En el tríptico de presentación del museo editado en 1998 por la Consejería de Cultura, decíamos que "De igual manera que la Historia [...] está sujeta a las variaciones que el propio grupo social realiza, el nuevo proyecto del Museo de Huelva ha de estar abierto a cuantas modificaciones se establezcan [...], por lo que debe ser considerado como algo dinámico, vivo y, por tanto, nunca acabado" "I. Esta frase es hoy más que nunca acertada ya que, si bien la propuesta de remodelación lanzada entonces continúa estando vigente y en esencia es la misma, las circunstancias que lo rodean han variado, lo que nos impele hacia nuevas conquistas. En efecto, el proyecto inicial no sólo ha producido buen efecto sino que su adecuación práctica proporcionará en su día la posibilidad de establecer mejoras museográficas que, indudablemente, afectarán a los planteamientos museológicos iniciales.

En síntesis, el organigrama de contenidos o áreas museológicas de la Sección de Arqueología quedó inicialmente establecido en once espacios o salas acotadas físicamente, cuyos contenidos debían mostrar la génesis del territorio onubense, así como la actividad humana sobre el territorio desde el Paleolítico hasta el momento del Descubrimiento de América. Los dos primeros espacios, denominados "Huelva en el Universo" y "Huelva en el planeta Tierra", se relacionan con dos circunstancias específicas del Museo de Huelva: por un lado, la aceptación del astrofísico onubense Juan Pérez Mercader para atender nuestra sugerencia de diseñar un área basada en sus investigaciones sobre el Big-Bang y la formación del planeta Tierra, cuya aspiración última sería la proposición de un futuro museo de la Ciencia y la Tecnología potenciado por el propio investigador. Por 
Es el hombre, su percepción y sus relaciones lo que se quiere significar...

otro, el necesario impulso que merecen las colecciones geo-paleontológicas del museo, derivadas de la desinteresada colaboración del Colegio Oficial de Ingenieros Técnicos de Huelva -que en su día proporcionó una amplia muestra de los minerales que la naturaleza onubense ofrece-, y del depósito establecido en diciembre de 1997 por el geomorfólogo Fernando Fernández Díaz; a estos conjuntos hay que añadir aquellos elementos producto de hallazgos fortuitos que, a falta de un espacio más idóneo, fueron depositados en nuestro museo ${ }^{12}$.

Los espacios siguientes reflejarían los avances científicos y técnicos de la humanidad a lo largo del tiempo mediante una serie de elementos o registros-guía que, concatenados entre sí y abiertos en abanico, posibilitarían la fácil asimilación de conceptos básicos como el tiempo, la evolución, el cambio o la permanencia de la cultura.

Como si de una obra inacabada se tratase, la exposición quedaría intencionadamente abierta a nuevas investigaciones, dando la posibilidad de añadir, si las circunstancias lo permitieran o así se requiriera, los avances alcanzados en periodos históricos posteriores. Es el hombre, su percepción y sus relaciones lo que se quiere significar $y$, a tal fin, el proyecto sacrifica los yacimientos -entendidos como unidades museográficas- a favor de los elementos culturales socialmente significativos que potencien la comprensión de aspectos tan variados como el arte, la minería, la alimentación o la vida cotidiana. Junto a éstos, otros como la religión, la escritura y el lenguaje, el adorno personal y la orfebrería, la tecnología o la guerra y el comercio podrán ser mostrados en connivencia de cuantos recursos didácticos se consideren necesarios para potenciar la comprensión e interpretación de los referentes histórico-culturales más destacados (reproducciones y copias de objetos hallados en otros puntos del espacio historico-temporal, fuentes escritas, paralelizaciones, programas multimedia, representaciones virtuales, etc.).

En cuanto a la Sección de Bellas Artes, sabido es que la gran mayoría de los museos de carácter provincial establecidos en la década de los setenta tenían como fondos propios los arqueológicos, mientras que las secciones de arte sirvieron en muchos casos para despejar los almacenes de otros museos y/o exponer las obras del ICCR, a los que se añadían alguna que otra compra esporádica a anticuarios de renombre y piezas escogidas procedentes de museos muy concretos, en nuestro caso del Museo de Bellas Artes de Sevilla y del actual MNCARS ${ }^{13}$. Se conformaban así, colecciones historicistas que poco o nada tenían que ver con la realidad social del museo en formación, dando lugar a profundas descontextualizacines. El caso del Museo de Huelva no es diferente y su Sección de Bellas Artes presenta una colección desigual, incongruente y segundona que, pese a loables intentos de revalorización establecidos en la década de los noventa ${ }^{14}$, no ha consolidado el maridaje deseado con la sociedad onubense.

En efecto, la colección del museo presenta insuficientes elementos de interés para significar su verdadera salvaguarda, pese a la existencia de elementos de la categoría de las ya mencionadas obras de Daniel Vázquez Díaz, el "San Juan Bautista predicando" - obra barroca atribuida a Alonso Rodríguez recientemente restaurada por el I.A.P.H. ${ }^{15}$, o la también citada donación realizada por Dña. Amalia Orduña Castellano ${ }^{16}$. Por ello, no será hasta los últimos años de la década de los noventa cuando, a través de una exitosa pero ciertamente agresiva política de exposiciones temporales, se haga posible el reencuentro del público con el museo, pero obligando a que la colección estable pasara a las salas de reserva.

Dadas las específicas características del público del Museo de Huelva, la propuesta que el proyecto museológico hace para la Sección de Bellas Artes se configuró en un principio sobre la base de una versátil compartimentación de los espacios expositivos, lo que facilitaría, de una parte, el mantenimiento del régimen de exposiciones temporales ya consolidado aunque evidentemente de una manera mucho más sosegada, y, de otra, la configuración de una exposición permanente centrada en una única temática: $E \mathrm{I}$ arte onubense del siglo $\mathbf{X X}$. 
Para articular esta propuesta se establecieron variadas alternativas que van desde el fomento de depósitos temporales a medio y/o largo plazo a través de contactos directos con los propios artistas, distintas instituciones o coleccionistas, hasta la propuesta de adquisiciones y préstamos institucionales, pasando por la invitación personalizada para el uso del taller de grabado a aquellos artistas que así se decida. Esta alternativa permitiría contar con obras de autores considerados esenciales para el entendimiento de la evolución de la plástica onubense, pese a las lamentables y más que probables omisiones que se producirían. Pero, concebido el museo con un espacio de comunicación dinámica y participativa, estas exclusiones justificarían no sólo posteriores remodelaciones sino que crearían nuevas expectativas en el público y los artistas, estableciéndose el intercambio intelectual al que necesariamente ha de invitar el museo.

Si para la Sección de Arqueología se contó con la colaboración de alguno de los más destacados arqueólogos de la provincia, para la de Bellas Artes nos ha sido de inestimable ayuda la obra de síntesis realizada por Jesús Velasco Nevado 17, la recopilación de catálogos de exposiciones realizadas en la provincia en las últimas décadas con los que cuenta el museo y las informaciones, sugerencias y anhelos que nos han aportado los artistas locales. De todo ello resultó la formalización de un plan desarrollado en siete espacios museológicos:

\section{El nacimiento del arte moderno}

La pintura historicista, el naturalismo y la plástica costumbrista: La Academia y las influencias foráneas (Fernando Martínez Checa, Manuel Cruz Fernández, Rafael Cortés Moreno...).

\section{Daniel Vázquez Díaz, pintor de Huelva}

\section{La escultura onubense a lo largo del siglo XX}

Antonio León Ortega, Santos Rojas, Pepe Noja, Rafael Mélida, Juan Manuel Seisdedos, Arte-Dos (Fernando Domínguez Rivas y Francisco Rivera Ruiz), Juan Carlos Castro Crespo, Alberto Franco, José Antonio Márquez, Fernando Bono ...).

\section{Pintores y acuarelistas del siglo $X X$}

- Pintura: José Caballero, Pedro Gómez, Mateo Orduña Castellano, Sebastián García Vázquez, José María Labrador, José María Franco, José Luis Domínguez, Florencio Aguilera, José Guevara Sandez, José Jiménez Quintero, Esperanza Abot...

- Acuarelistas: Alfonso Aramburu, Emilio Gil Vázquez, José María Franco...

\section{Hacia el siglo XXI}

Isidro Overli, Juan Manuel Seisdedos, Pedro García Ramos, Juan Carlos Castro Crespo, Buli, Pedro Rodríguez, Manuel Sicet, Antonio Belmonte, Tomás García Asensio (Saltés), Enrique Romero Santana, Joaquín Mora...

\section{Arte joven}

Víctor Pulido, Juan Manuel Vidal, Javier Villegas, Angustias García + Isaías Griñolo, Fátima MarceIo, Ana Ma Caliz, Caridad Orta, Carmen de la Corte, Amalia Feu...

\section{Obra gráfica}

Marcial Muñiz Mendoza, Daniel Vázquez Díaz, Juan Carlos Castro Crespo, Antonio Belmonte, Faustino Rodríguez, Diana García, Asociación de grabadores de Huelva...

\section{A grandes necesidades, pequeños remedios: la adecuación del espacio arquitectónico del museo}

¿Quién no ha soñado con solventar los pequeños y grandes inconvenientes estructurales de nuestros museos?: pasillos estrechos que impiden la accesibilidad, ascensores que llevan a ninguna parte, climatizaciones defectuosas, almacenes reducidos, espacios para la dinamización inexistentes, instalaciones eléctricas incapaces de soportar la fuerza de las nuevas tecnologías... Establecer el programa de necesidades que anualmente nos solicitan las distintas Delegaciones de Cultura, se nos antoja la "carta a los Reyes Magos" de un muchacho a punto de despertar a la pubertad: "creo, pero no creo". Sin embargo, en algunas ocasiones, las circunstancias juegan a nuestro favor y la necesidad de cumplir las normativas vigentes en materia de seguridad y habitabilidad permiten acometer cambios que potencian una adecuación de los espacios museísticos. En efecto, la necesaria transformación de ascensores e instalación eléctrica, así como la obligatoriedad de establecer unos servicios higiénicos para discapacitados, eliminar las filtraciones existentes y fijar circuitos de evacuación en caso de catástrofe, han dado la ocasión al Museo de Huelva para un acercamiento, sereno y armónico, hacia algunas de las actuales propuestas museográficas. Además, hemos tenido la suerte de contar con un arquitecto poco convencional capaz de adaptarse a nuestras necesidades y exigencias con un limitado presupuesto. El resultado es un plan que, bajo el nombre de "Proyecto Básico de Reforma y Ampliación del Museo de Huelva", actualmente se encuentra en vías de aceptación y cuya realización posibilitará importantes mejoras espaciales que podemos resumir en los siguientes punto (Figs. I-7)

- Eliminación de filtraciones mediante la impermeabilización y acondicionamiento de los muros maestros.

- Adecuación de la zona de carga y descarga, ampliando los espacios para estas actividades.

- Ampliación del espacio útil de almacenamiento en el área de reserva arqueológica, así como su mejora climática mediante la instalación de un sistema de aireación natural y creación de una "sala seca. 
Figuras 1, 2 y 3 . Plantas baja, primera y sótano reformadas
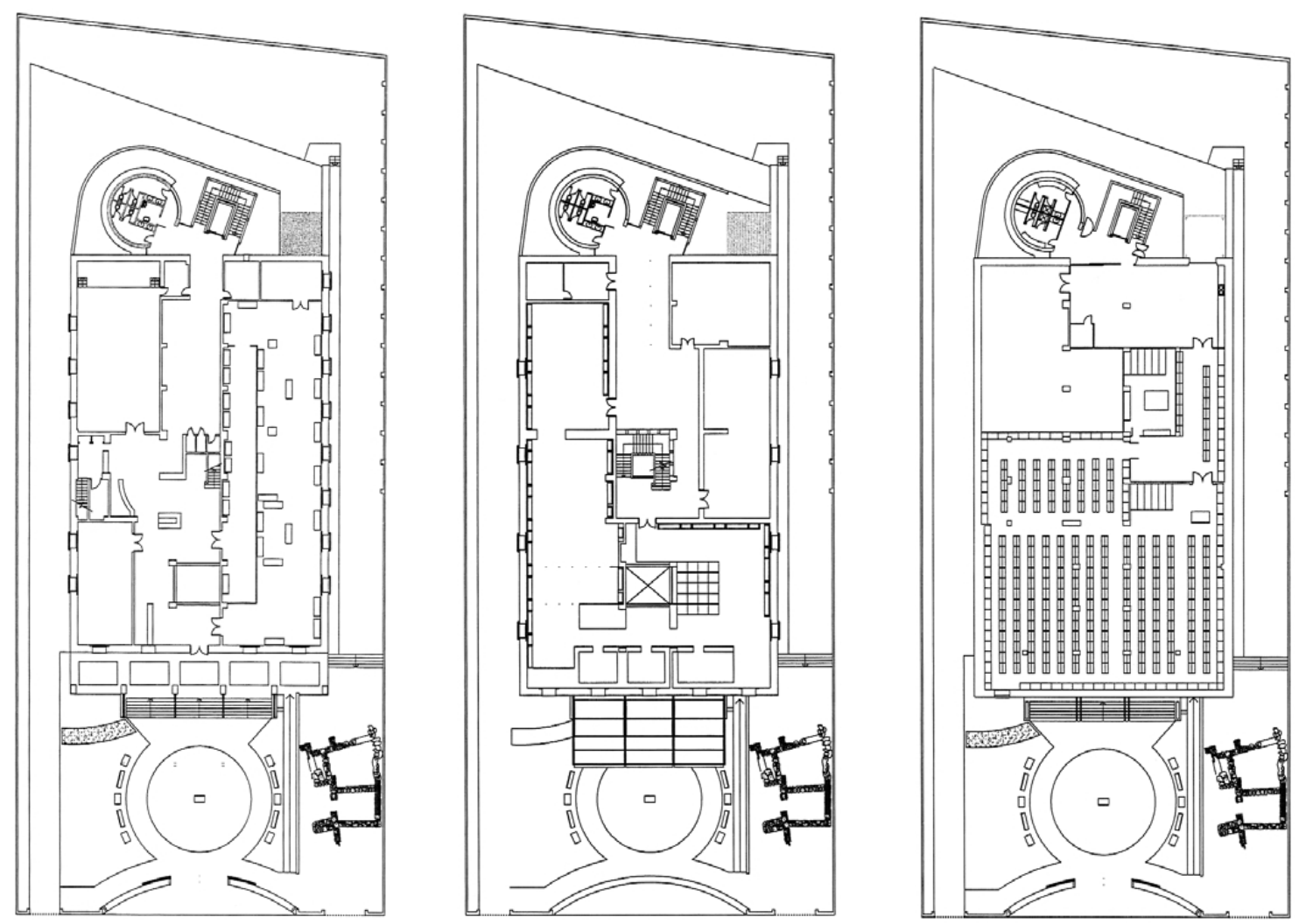

- Construcción de dos torres adosadas a la trasera del edificio que albergaran, una, el elevador de usos múltiples con acceso discriminado y la escalera de emergencia y, otra, los servicios higiénicos y zonas de descanso de personal. Esta actuación corrige uno de los principales problemas de adaptabilidad a la normativa, al tiempo que elimina las dificultades de accesibilidad para público y obras liberando, con ello, unos espacios hasta ahora ocupados por las zonas de tránsito interno -escaleras interiores, servicios higiénicos, etc.-, que permitirán la creación de unas áreas idóneas para el descanso y la dinamización de las colecciones. Con esta actuación se pretende de incentivar de forma clara y rotunda la fuerte volumetría del edificio, intensificándola y realzándola a través de estos dos nuevos volúmenes.

- Potenciación del eje que centra la composición interna de las salas expositivas, distribuyéndolas a izquierda y derecha y dejando el centro como zonas de descanso con exposiciones alternativas y temporales.

- Adaptación a la normativa de los servicios de guardarropía y cabinas del personal subalterno.

- Adecuación de los circuitos de desalojo del edificio en caso de catástrofe.

- Establecimiento y adaptación de los servicios públicos para discapacitados físicos, según normativa vigente.
- Adecuación de los espacios expositivos a la nueva disposición arquitectónica, lo que permitirá una circulación más coherente.

- Adecuación del área de reserva de la sección de Bellas Artes.

- Individualización del espacio destinado a talleres mediante la creación de tres áreas: taller de grabado, taller de restauración y gabinete numismático (Fig. 4b). En este apartado, existe la posibilidad de establecer uno o varios de los paramentos interiores de cristal, lo que posibilitaría su visualización por parte del público sin que se vieran afectadas las actividades técnicas en desarrollo.

- Creación e individualización de un espacio para el depósito documental (Fig 4b).

- Reestructuración del jardín de acceso eliminando obstáculos y estableciendo un ingreso peatonal directo, aspectos importantes dada la sensación de prohibición que despierta el vallado actual. Con el mismo criterio, se diseña una entrada para mercancías y vehículos, al tiempo que se acondiciona el jardín para su uso público. En este "jardín museográfico" podrán ser visitadas las restituciones arqueológicas derivadas de las excavaciones de urgencia que los técnicos del museo hubieron de acometer en el año 1998, la variada y centenaria flora regional que la parcela acoge y un espacio diseñado como sala de exposiciones al aire libre. 
Figuras $4 A$ y $A B$. Planta de azotea y segunda reformadas
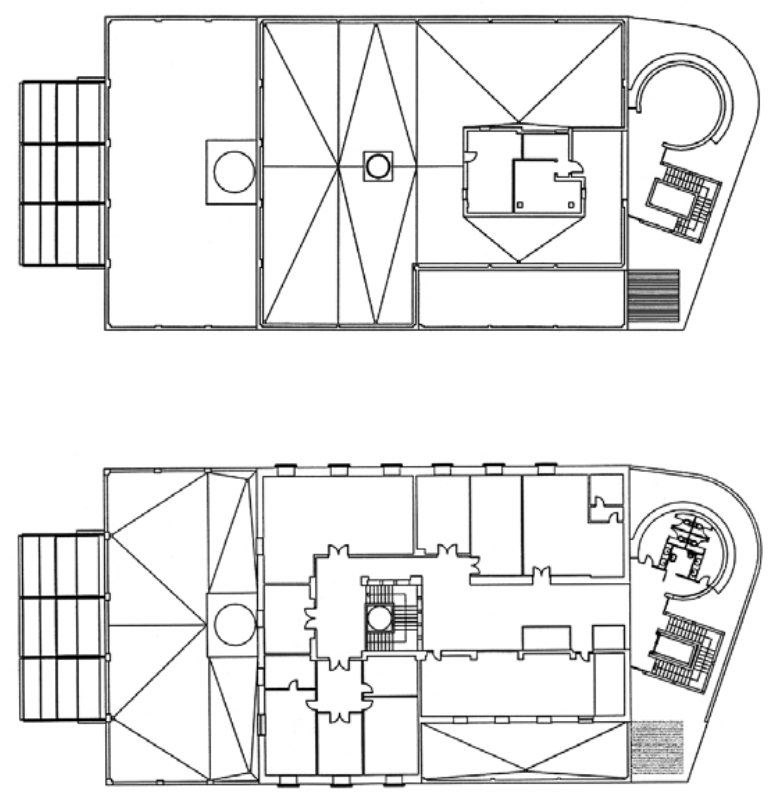

- Remodelación de la fachada principal del edificio eliminando su anodina imagen mediante el establecimiento de una visera que, a modo de aquellas veladuras que tanto utilizaron los marineros romanos en construcciones auxiliares como toldos de sombras, comunique su relación con la ciudad deseada. En esta nueva concepción de la fachada, los vanos quedan convertidos en hornacinas que albergarán diversas reproducciones escultóricas, potenciando la recuperación del concepto clásico del museo (Figs. 5A y 5B).

- Remodelación de toda la zona de vestíbulo para albergar de forma más contundente la noria romana con la que cuenta el museo, pieza clave del mismo que podrá ser contemplada suspendida del techo, en dobles alturas y desde todas las plantas.
Prueba de la estrecha colaboración entre conservadores y arquitecto, el proyecto no sólo se adapta a la propuesta museológica establecida en el apartado anterior, sino que la mejora sustancialmente. Así, una vez hayan concluido las obras, la planta principal contará con una amplia zona de recepción donde quedará ubicada la expenduría de entradas, el directorio general, la tienda y el directorio de contenidos de la sala primera de arqueología. Una pequeña sala de exposiciones temporales, el salón de actos, conserjería y servicios sanitarios darán paso al amplio vestíbulo donde quedará instalada la primera zona de descanso, pensada como un espacio multiuso adecuado para establecer servicios paralelos relacionados con las propuestas expositivas. Se pretende con ello la creación de un área donde el público visitante pueda, además de descansar, establecer un diálogo diferenciado con la temática de las exposiciones a través de un paquete de ofertas didácticas específicas y personalizadas. En un primer momento estos lugares, pues la misma idea se repite en la primera planta, incluirán una pequeña videoteca especializada y zona de consulta bibliográfica y documental pero, con el tiempo, deberían entenderse como pequeños talleres de dinamización socio-patrimonial (Fig. I).

La planta primera se distribuye en tres salas de exposición, un vestíbulo de amplitud y definición similar al descrito para la planta principal y dos salas de reserva, una específicamente diseñada para las obras en tránsito y, otra, restringida a la colección permanente. En esta distribución, las estancias laterales quedan concebidas como espacios expositivos de carácter temporal, mientras que la central albergará la continuación de la muestra permanente de arqueología, estructurada desde la Romanización hasta la Época de Colón y organizada a través de diferentes escenografías (Fig. 2).

Como se desprende de nuestra descripción, la importante merma porcentual en el espacio tradicionalmente reservado para Bellas Artes parece imposibilitar la muestra de las obras que conforman

\section{Figuras $5 \mathrm{~A}$ y $5 \mathrm{~B}$. Proyecto de reforma y ampliación del museo provincial de Huelva}
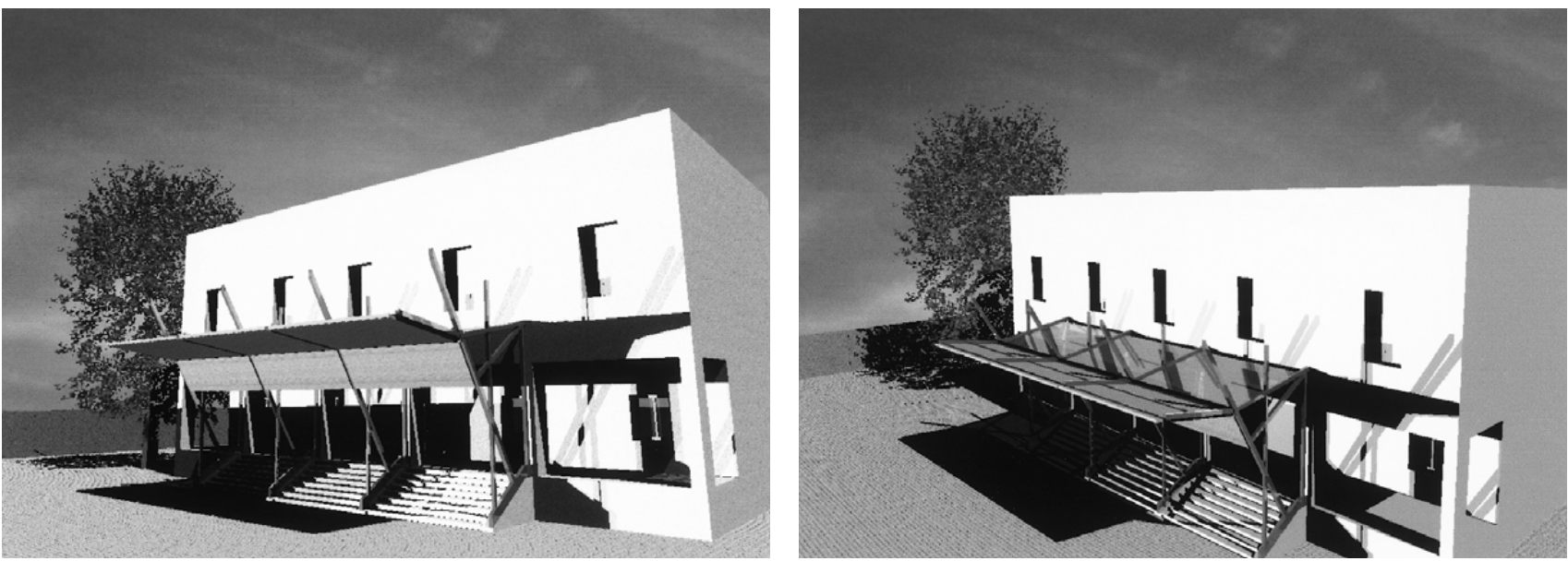
Figura 6. Fachadas principales interior y exterior reformadas

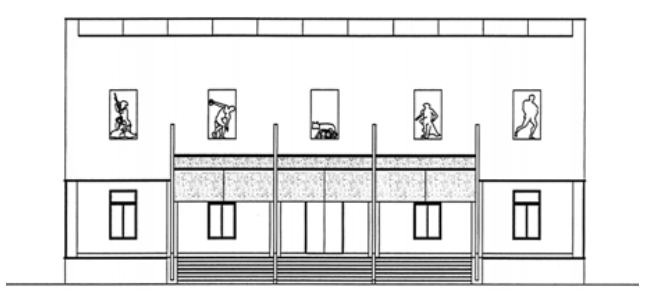

nuestro repertorio permanente y, en efecto, así es. La solución a este grave problema se plantea en dos vertientes de actuación: mientras se consolida la propuesta de colección que hemos proyectado para el museo onubense, ésta tendrá el tratamiento de temporal, quedando integrada en la propuesta anual de exposiciones. Pese al riesgo que ello supone, asumimos esta decisión al evidenciar, de nuevo, la desestructuración que en la actualidad contempla la colección, así como las dificultades que conlleva su mejora real.

La segunda propuesta resulta en estos momentos ciertamente utópica, pero no por ello deja de tener un aire de realidad elemental. Para algunos grupos de opinión destacados de la ciudad, el Museo de Huelva resulta pequeño para albergar su importante colección arqueológica y su necesaria colección artística. Por ello, desde hace largo tiempo se viene reclamando su ampliación espacial mediante la creación de una segunda sede pensada como Museo de Bellas Artes. Si éste es el anhelo de la sociedad onubense, no resulta descabellado sumarnos a esta corriente proponiendo como futura sede de nuestra Sección de Bellas Artes alguno de los denostados espacios arquitectónicos existentes en la ciudad. Cualquiera de ellos puede alzarse como icono de la formulación urbana de Huelva y símbolo inequívoco de los cambios económicos, sociales y culturales provocados por la vertiginosa industrialización sufrida en el último tercio del siglo XIX'18.

Actuación a todas luces interesante que posibilitaría la formulación de espacios expositivos idóneos para las tendencias plásticas actuales al tratarse, en general, de naves industriales para la producción de manufacturas. La consecución de uno de estos edificios como sede de la Sección de Bellas Artes permitiría, a su vez, la adecuada contextualización de parte, si no de toda la colección del museo, al tiempo que potenciaría la recuperación del entorno urbano como referente cultural de la sociedad onubense. En este sentido, parece oportuno reflexionar sobre el papel social que ha de cumplir el museo y sobre la capacidad que se le supone como catalizador en la necesaria y obligada visión globalizadora del Patrimonio 19. Señalar, por último, la eventualidad que presenta el edificio colindante al actual museo; se trata de una nave industrial con amplios vanos laterales de clara raigambre modernista, adosada a la trasera de una pequeña vivienda unifamiliar cuya configuración ex-

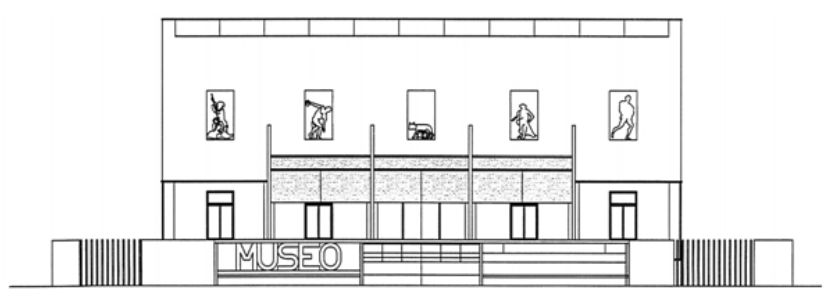

Figura 7. Fachada lateral derecha y sección longitudinal reformadas

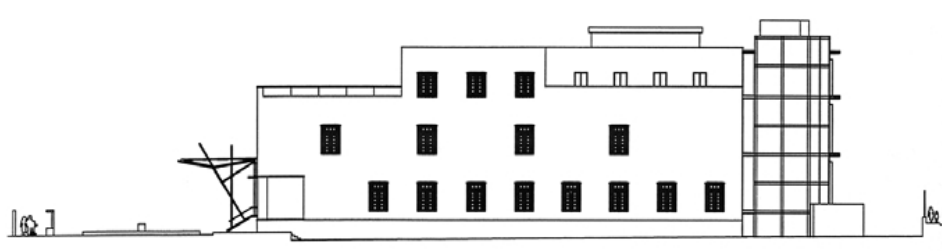

FACHADA LATERAL DERECHA REFORMADA

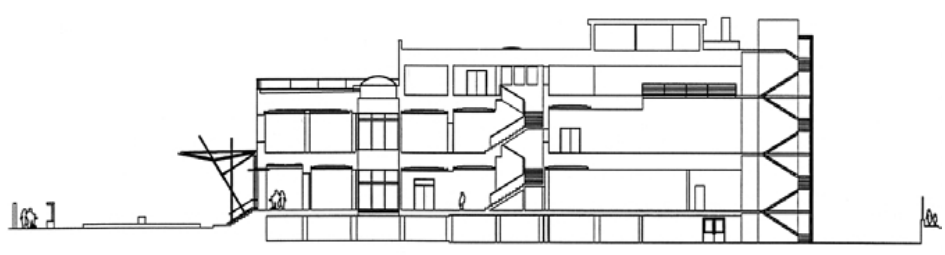

SECCION LONGITUDINAL REFORMADA

terna exhibe el ineludible exotismo británico que caracteriza a la arquitectura onubense de las primeras décadas del siglo $X X^{20}$ (Figs. 8A y 8B).

\section{La nueva museografía propuesta}

Los museos son lugares vivos, acogedores y participativos donde la gente se comunica mediante el descubrimiento, el aprendizaje, la interpretación y la visualización de los elementos materiales que conserva. Éste es, en definitiva, el mensaje que queremos transmitir desde Huelva a través de una adecuación de los espacios museográficos y la puesta en funcionamiento de un buen número de actividades. Analicemos, pues, estos objetivos con una rápida descripción de las distintas propuestas:

Sin duda, nuestro primer objetivo es provocar un cambio en la actual percepción que se tiene de la Institución. El museo debe pasar de considerarse como lugar distante e inapetente, para convertirse en un espacio de lo cotidiano cuya presencia y contenidos inviten a su apropiación. Imbuidos en esta necesidad, se ha proyectado un área de recepción ajardi- 
nada donde lo importante no sea tan sólo "el establecimiento de una pantalla vegetal que colabore en la estabilidad medioambiental del edificio" sino, más que nada, el fomento de las capacidades creativas del individuo, frente al ruido, las prohibiciones y las soledades imperantes en la vida urbana. Un territorio donde el hombre pueda adueñarse del mundo de las formas y de los objetos, donde hallar las claves de nuestra cultura y de nuestra historia.

En esta búsqueda sosegada de referentes, el interior del museo se proyecta envuelto en una humanizada y confortable atmósfera que provoque el goce por descubrir, por ver, por aprender, por compartir... Aquí, el vestíbulo, ofreciendo la información precisa para invalidar la inquietud; allí, las salas expositivas, incitadoras recurrentes a la complicidad; más allá, las áreas de descanso, de participación y de íntima comunicación. Y, en medio, como si de un secreto a medias se tratase, las puertas hacia los laboratorios, los almacenes, las salas de reserva: investigación y orden, entrañas ocultas donde hombres y mujeres se afanan por comunicar el pasado, el presente $y$, más que nada, el futuro. Todo parece dispuesto; todo, intencionadamente pensado. Nuevas perspectivas se abren en este remodelado museo donde len-
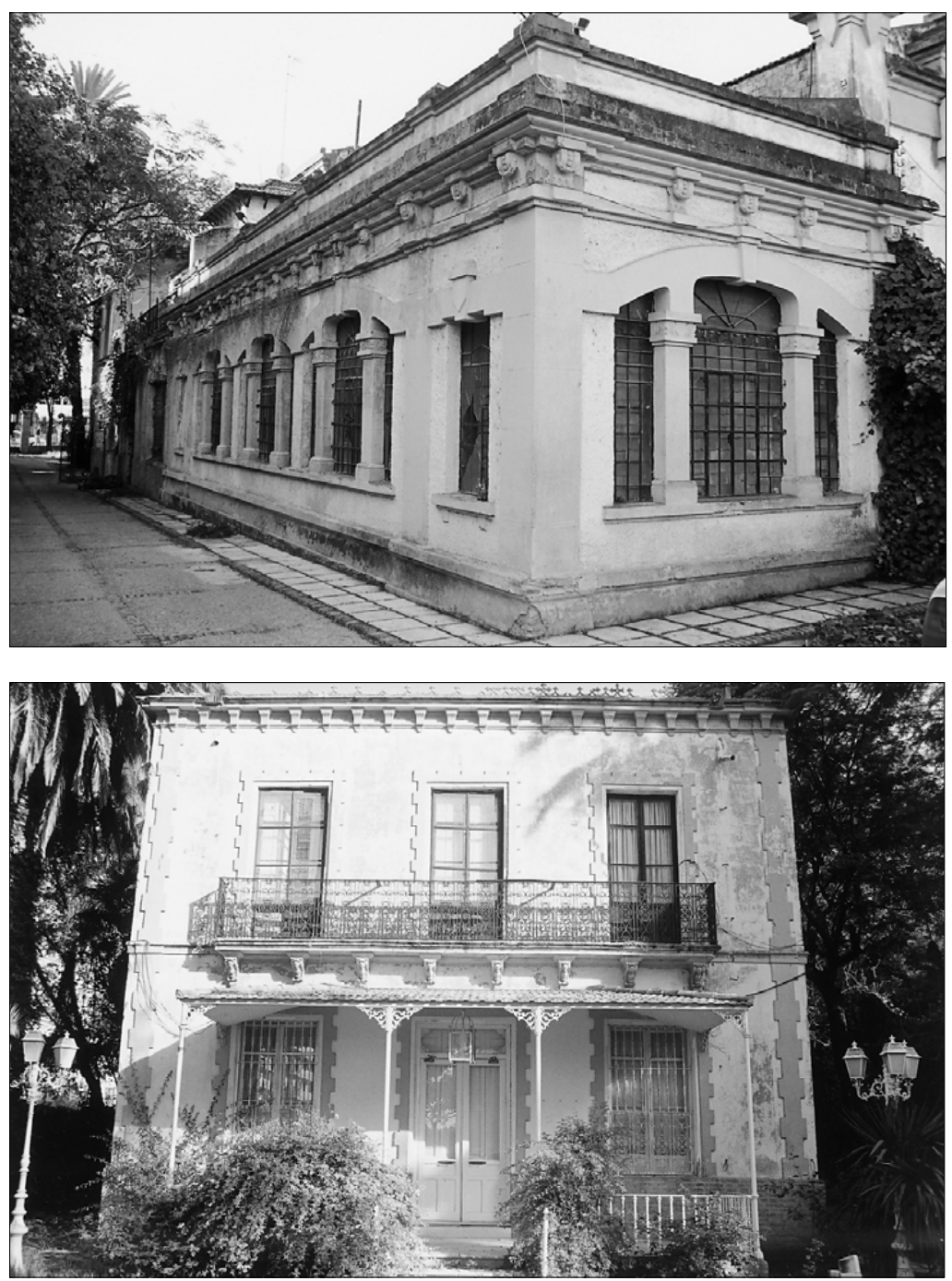

tamente, con la querencia y la cadencia que estas cosas requieren, se van multiplicando los servicios:

- El I 8 de Mayo del pasado año se puso en marcha la asociación de "Guías Voluntarios de la Tercera Edad" que, a buen seguro, favorecerá la implantación social del museo. Superada ya su fase de preparación, comenzará sus actividades en el mes de noviembre. Éstas, centradas básicamente en la oferta de visitas guiadas para grupos infantiles y de Tercera Edad, se evidencian, también, como un eficaz y permeable elemento de participación social, estableciendo nuevas fórmulas de comunicación y relación entre el museo y un tipo de público específico que tiene todavía capacidad para aprender y enseñar pero que, al tiempo, exige la creación de redes de intercambio propias.

- También presentada el "Día Internacional de los Museos", la asociación "Museo 2000"(Asociación de Amigos del Museo), centrará sus actividades en dos ámbitos: la implantación del museo en la sociedad y la canalización de los esfuerzos colaboradores que rodean al mismo. Particularizarán su actuación a través de la preparación y posterior coordinación de grupos de voluntarios para la interpretación de los futuros espacios de dinamización presentes en el proyecto, la organización de elementos que faciliten la contextualización de los objetos y la estructuración de fórmulas de intercambio que sirvan como catalizadores entre la Institución y el público general mediante el debate participativo. Así mismo, se pretende que de cobertura a la actividad colaboradora existente, cuya efectividad en muchas ocasiones se ha visto mermada por falta de la estructuración legal oportuna.

- La obligada adecuación de las salas permanentes de exposición y de los futuros servicios programados, nos provoca la necesidad de efectuar un seguimiento pormenorizado de nuestros visitantes. Por esta razón se ha iniciado una campaña de análisis de público cuyos resultados posibilitarán la obtención de información objetiva para el examen de factores como la accesibilidad de la información, la confortabilidad de los espacios, el acierto en la selección de los contenidos o las preferencias temáticas de los visitantes. Así mismo, se prevee la presentación y debate público del proyecto de remodelación una vez haya sido aceptado, ajustando las propuestas museográficas a las necesidades y preferencias del público.

- En colaboración con el Área de Didáctica de las Ciencias Sociales de la Universidad de Huelva, se están diseñando los materiales de apoyo a la difusión patrimonial necesarios para que el museo se constituya como un centro de interpretación básico de la estructura educativa de la sociedad, tanto desde la perspectiva de la educación formal (básicamente público escolar) como de la no formal o informal. En este sentido se han realizado ya algunas experiencias, como la publicación de la pe- 
queña guía didáctica para la exposición "Tartessos: del mito a la realidad", génesis de nuestra propuesta permanente de arqueología 21 . Y, en misma línea, está previsto también el establecimiento de recursos dirigidos a públicos específicos, favoreciendo la interpretación de los objetos desde perspectivas diversas. Así, parece interesante trabajar sobre las necesidades que presentan los grupos familiares no guiados, en los que el cabeza de grupo se ve por lo general con incapacidad para actuar como catalizador de la experiencia.

- El Museo de Huelva lleva algún tiempo realizando experiencias relacionadas con las posibilidades educativas y de implantación social que presentan las áreas internas, mediante visitas guiadas restringidas. Los resultados manifiestan que una explicación razonada, una visualización objetiva y la demostración empírica de algunos de los trabajos que forman parte de la conservación, posibilitan una respuesta inspiradora y positiva hacia la institución encargada de custodiar y mantener los rasgos objetuales que definen nuestra cultura. De igual forma, la inclusión de las zonas de reserva y talleres de restauración e investigación en los circuitos de visita estimula el deseo de conocimiento e infunde actitudes proteccionistas en el público, favoreciendo la implantación de la idea, tanto tiempo perseguida, de entender como una obligación comunitaria la conservación del patrimonio y de percibir a los museos, como uno de los instrumentos que la sociedad tiene para hacerse cargo de esta obligación.

Atendiendo a este razonamiento, se prevee la estructuración de los fondos y talleres con la capacidad técnica suficiente para absorber este tipo de visitas, mediante la organización de un circuito interno didáctico y el establecimiento de los mecanismos necesarios para la reducción del impacto medioambiental que sobre la obra supondría su apertura pública. Es obvio que estas visitas en ningún caso podrán considerarse cotidianas pero, de igual manera que se debate la función social del arte y la implicación que ello significa sobre el productor y la producción artística, debemos plantearnos la función social del patrimonio y sus implicaciones conceptuales sobre la conservación del mismo.

- La exposición constituye el lenguaje propio del museo, su sistema de comunicación, pero la gran mayoría del público no es especialista y necesita de apoyos que le permitan conocer el significado y los valores ocultos de los objetos que se exhiben 22 . Para resolver este problema lo normal es concentrar nuestros esfuerzos en la elaboración de materiales más o menos didácticos y en los servicios de visitas guiadas. Sin embargo, para la tipología de público que en general absorbe el Museo de Huelva esto no es suficiente, ya que nuestro problema es la captación de un público repetidor, hecho que no se logrará sin establecer mecanismos que permitan la visualización diversificada de las coleccio- nes y un grado de satisfacción suficientemente fuerte para su conquista. En este sentido se nos ocurren mil y una actividades, muchas de ellas puestas ya en marcha, que facilitarán la diversidad y favorecerán la dinamización no sólo de las colecciones, sino del museo en sí mismo. Así, se han realizado experiencias con la participación del artista como guía de su propia creación y se han organizado coloquios en sala donde la obra era apreciada, en unos momentos, como creación individualizada y, en otros, como soporte para introducirnos en un debate de temáticas más complejas.

En esta misma línea, se presagia la creación de talleres-coloquio donde los "maestros" analicen la técnica artística, al tiempo que documentan y discuten sobre la evolución sufrida en el paisaje onubense, los cambios en la forma de vida o en la tipología de los objetos representados. También, se están organizando ciclos donde personajes de claro reconocimiento social comenten de manera abierta cuál es el objeto del museo que más les inspira, convirtiéndose ellos en agentes interpretativos al tiempo que en elementos de atracción. Y, en colaboración con el Conservatorio de Música, se establecerán audiciones inspiradas por la temática de las obras expuestas.

Todas estas experiencias supondrán una evidente incomodidad para aquellos visitantes acostumbrados a pasear por unas salas casi desiertas pero, por contra, facilitarán la comunicación entre la obra y el público haciendo del museo un verdadero lugar para la comunicación.

\section{Hacia la implatación del museo en la sociedad}

No todas las actividades que se proponen pueden realizarse en las salas. Muchas, necesitan de lugares más adecuados donde no se entorpezca al resto de visitantes; otras, del territorio que circunscribe al propio museo. Para las primeras, el proyecto de remodelación diseña unos espacios estructurados en las áreas actualmente ocupadas por buena parte de las instalaciones interna del edificio (servicios, escalera interior, ascensores, etc.). El resto, nos introduce en problemas más complejos que implican la necesidad de relacionar nuestras colecciones con el escenario donde se produjeron, de contextualizar con efectividad los objetos eliminando las barreras que impiden su observación como producciones humanas, como elementos ejemplarizadores de las fórmulas de relación del hombre, a través de las cuales se establecen los referentes identificadores de la comunidad.

Como bien dice Concha San Martín, el museo, por su carácter de institución vinculada a la protección del patrimonio tiene la ventaja de crear nexos que relacionan la investigación con el ciudadano, lo que le dota de una situación privilegiada para el desarrollo de una adecuada difusión patrimonial, entendida 
como la fórmula idónea para potenciar el acceso y conocimiento a los bienes que integran ese patrimonio ${ }^{23}$. En el mismo artículo la autora establece que la comunicación objeto-público debe ir encaminada a la necesaria revalorización del objeto mediante su contextualización espacial y/o funcional, formulados a través de distintos mecanismos.

Desde el Museo de Huelva, consideramos que uno de estos mecanismos es la ocupación del territorio más cercano -sea éste urbano o rural- mediante su musealización, lo que posibilitaría al visitante la recreación de su propio contexto visual y conceptual. En este sentido, quizás la experiencia más interesante a la que nos hemos visto sometidos fuera la generada por las excavaciones de urgencia realizadas en 1998 por los técnicos del museo, convenientemente analizada por nuestros colaboradores José María Cuenca y Myrian Martín 24. Por circunstancias específicas que ahora no vienen al caso, el museo hubo de realizar estas dos excavaciones en el casco histórico de Huelva ${ }^{25}$, marcando como uno de sus principales objetivos la comunicación inmediata de los resultados a los distintos ámbitos sociales de la ciudad, a fin de paliar alguna de las deficiencias que los museos soportan: descontextualización de los objetos, distanciamiento de los intereses del ciudadano, etc. La idea era plantear en la misma excavación un centro de interpretación del patrimonio arqueológico con el tratamiento de sala museal, articulándose la visita con dos vertientes: por un lado una sesión de puertas abiertas a toda la ciudadanía con periodicidad semanal y, por otro, la difusión específica en el ámbito escolar. En ambos casos, el objeto era potenciar actitudes conservadoras y valorativas del patrimonio arqueológico. Los resultados de las encuestas que se realizaron en el transcurso de las distintas actividades programadas, han proporcionado una interesante información sobre el grado de compromiso que tiene la sociedad onubense respecto a la conservación de su patrimonio, sobre sus necesidades de conocimiento cultural como factor de identificación social y sobre la valoración del museo como elemento de apoyo para el entendimiento de los valores histórico-culturales que se encierran en ella.

El éxito de la experiencia obliga también a un cambio de actitud por parte del museo, por cuanto se ve en la necesidad de proporcionar nuevos elementos referenciales al visitante, mediante la organización de una estructura que le permita la comunicación abierta y directa con el entorno territorial inmediato. Ejemplos de esta nueva vía de actuación son las propuestas de circuitos interpretativos que faciliten los puntos estratégicos desde donde poder apreciar la evolución socio-histórica de la ciudad, o el establecimiento de rutas complementarias relacionadas directa o indirectamente con los elementos arqueológicos y artísticos analizados en el museo. Sobre este tema no se debe obviar la motivación espontánea que surge al visualizar directamente los lugares patrimoniales, ni la interacción de los múltiples conceptos que concurren en las visitas de carácter cultural a los escenarios donde se establecen las experiencias cotidianas de los individuos.
Ello no supone el abandono de otros tipos de enlaces museográficos que favorezcan la comprensión de determinados aspectos socio-históricos de difícil asimilación, a pesar de su eventual percepción in situ. Muy al contrario, las simulaciones virtuales diseñadas como hipotéticas reconstrucciones de la realidad histórica se presentan, entonces, como una nueva alternativa para canalizar la percepción patrimonial a través del museo 26 .

Por último, para que estos nuevos mecanismos de contextualización espacial de las colecciones se hagan efectivos, el museo debe diseñarse como un centro de coordinación donde se disponga de la información básica y de los materiales necesarios para la interpretación territorial a través de los distintos referentes patrimoniales existentes en la provincia. En efecto, parece incongruente proponer nuevos circuitos y rutas interpretativas obviando las propuestas culturales establecidas por colectivos municipales, comarcales o provinciales cuya actividad aconseja una estructuración administrativa que impida su dispersión.

Por sus características específicas, el Museo de Huelva -el único de la provincia dependiente directamente de la Administración, sea ésta regional o nacional-, podría posicionarse como este cada vez más necesario elemento de globalización, centralizando la información para que el público visitante pueda beneficiarse de una oferta cultural en estos momentos disgregada, pero efectiva a la hora de recrear el contexto territorial de la provincia.

Esta actuación no supondría una intromisión en la gestión de ninguno de los centros, puesto que su única función sería la creación de un nuevo servicio diversificador de la oferta, proponiendo circuitos que favorezcan la contextualización y complementen los discursos museológicos establecidos en cada uno de ellos. Así, por ejemplo, cuando el visitante analice los elementos objetuales que simbolizan la Era del Descubrimiento, utilizará como elementos de apoyo las escenografías ofrecidas por el "Muelle de las Carabelas" (La Rábida, Palos de la Frontera), mientras que para introducirse en la minería antigua se le sugerirá una visita al "Museo minero de Riotinto" (Riotinto). La diversidad temática del proyecto museológico propuesto por el Museo de Huelva permite una conexión con todos los centros actualmente existentes en los que, sin duda, quedan incluidos también los "Centros de interpretación" de los distintos parajes o parques naturales y los museos y centros de carácter artístico o etnográfico como el "Museo Vázquez Díaz" (Nerva), la "Casa Grande" (Ayamonte), el "Museo de la Villa" (Almonte) y la "Casa Dirección" (Valverde del Camino), por poner nuevos ejemplos.

En contrapartida, cada uno de estos centros facilitaría la información para la visita al Museo de Huelva creando, así, un circuito cultural beneficioso para todos, ya que se estaría fomentando la movilidad y la dinamización del visitante cultural. 
I. En este paso fue de gran importancia las aportaciones recibidas por diversos especialistas, entre los que destacamos por su interés, el aporte bibliográfico proporcionado por Juana Bedia, conservadora del Museo, las largas conversaciones mantenidas con el Dr. Francisco Gómez Toscanos, en cuanto a los contenidos de la sección de arqueología, y con el artista onubense Juan Manuel Seisdedos en relación a los aspectos expositivos-museográficos.

2. J. Leguina y E. Baquedano (Edrs.): Un futuro para la memoria. Sobre la administración y el disfrute del Patrimonio Histórico Español, capítulo 2: "Patrimonio Arqueológico y Etnológico", p. p. 57-98. Madrid, 2000.

3. M. Osuna: "Avance del proyecto de remodelación del Museo de Huelva". En: Domínguez, C., Estepa, J. y Cuenca, J.Ma (eds.): El Museo, un espacio para el aprendizaje, p. 92. Universidad de Huelva, Huelva, 1999.

4. Velasco Nevado, J.; Muñoz Rubio, V. y García Rincón, J. Ma: Catálogo de Bellas Artes del Museo Provincial de Huelva, p. I5. Diputación Provincial, Huelva, 1993.

5. Esta falta de identificación se hace palpable cuando recordamos que, hasta hace poco, era necesario adjetivar al museo con frases como "frente al Palacio de Justicia" o "frente al Hotel Luz" para que muchos de nuestros conciudadanos acertaran a saber la ubicación del Museo de Huelva, por otra parte, el único de la ciudad. Por fortuna y gracias a la política de implantación llevada a cabo en los últimos años, la situación está cambiando pese a un cierto equívoco de funciones entre la Casa de Cultura-Casa Colón y el Museo.

6. Por Orden del 13/10/98 es aceptada por parte de la Consejería de Cultura de la Junta de Andalucía la donación de Dña. Amalia Orduña Castellano de 37 obras de su hermano Mateo (BOJA n 128 de 10 de noviembre de 1998).

7. Como la reciente adquisición por parte de la Consejería de Cultura de una carpeta de grabados de José Caballero (Expediente $n^{\circ}$ C99I78SM2IIP).

8. Se encuentra en trámite de aceptación, entre otros el depósito de José Mora Galiana sobre una obra de Juan Manuel Seisdedos o el realizado por el artista Juan Manuel Vidal.

9. C. Pereo Serrano: "Etnografía en el Museo". Cuadernos divulgativos del museo, 5, p. 3-4. Museo de Huelva, Junta de Andalucía, Delegación en Huelva. Huelva, s.f.

10. El Museo de Huelva colabora decididamente con aquellos municipios interesados en la formalización de instituciones museísticas de carácter etnológico, tal es el caso del Museo de la Villa (Almonte) con el que se ha establecido una estrecha reciprocidad, o la "Casa Dirección" de Valverde del Camino.

1 I. El Museo de Huelva. Junta de Andalucía. Consejería de Cultura. Dirección General de Instituciones del Patrimonio. Sevilla, 1998.

12. Sirva esta nota de agradecimiento a éstas y a cuantas personas vienen colaborando con nosotros para lograr un museo más participativo y activo.

13. J. Velasco; V. Muñoz y J. Ma García, ob. cit., p. 7-9. Huelva, 1993.

14. J. Velasco Nevado y Santos Rodríguez, E.: "El Museo de Huelva: un itinerario a través de la Historia y su proyección de futuro". Cuadernos divulgativos del Museo, 3, Huelva 1989. J. Ma Morillas Alcázar: "La colección de pinturas barrocas del museo de Huelva, un olvido injusto". En: Del siglo de Velázquez, arte religioso en la Huelva del siglo XVII, p. 51-66. Gabinete Pedagógico de Bellas Artes, Junta de Andalucía, Delegación de Cultura. Huelva, 1999.
15. G. Ferreras, R. Ojeda, L. Pérez del Campo y E. Villanueva: "Intervenciones del IAPH en instituciones del Patrimonio Histórico: servicios y proyectos de conservación (19961998)". Boletín del IAPH, 25 (diciembre 1998). Sevilla, 1998. J. Ma. Morillas Alcázar: ob. cit., p. 61.

16. Orden de 13/10/1998 de la Consejería de Cultura, publicada en el BOJA $n^{\circ} 128$ de 10 de noviembre de 1998. J. Velasco Nevado: Mateo Orduña Castellano, pintor de Huelva. Consejería de Cultura, Delegación provincial de Huelva. Huelva, 2000.

17. J. Velasco Nevado: Historia de la pintura contemporánea en Huelva: 1892-1992. Diputación de Huelva, Servicio de Publicaciones, Col. Investigación, 7. Huelva, 1993.

18. Parece interesante contemplar la Industrialización y sus contradicciones como paisaje idóneo de la producción artística onubense a partir de finales del XIX. Sobre la repercusión emocional que supone para el onubense la brusca entrada en la Era Industrial, consultar a Asunción Díaz Zamorano y la bibliografía que aporta en su obra Huelva, la construcción de una ciudad. Premio Díaz Hierro de Investigación 1998. Ayuntamiento de Huelva, Huelva, 1999.

19. J. Ma Cuenca López y C. Domínguez Domínguez: "La difusión del patrimonio urbano. El diseño de programas y actividades desde la perspectiva didáctica". En: J.C. Martín de la Cruz y R. Román Alcalá (edrs.): Las ciudades históricas. Patrimonio y sociabilidad, Actas del primer congreso internacional celebrado en Córdoba del 15 al 17 de abril de 1999, p. p. 53-60. Córdoba, 2000.

20. Montaner Roselló, J. y otros: Edificios de interés de la ciudad de Huelva. Colegio Oficial de Arquitectos, Huelva 1978.

21. Díptico divulgativo editado por la Consejería de Cultura de la Junta de Andalucía, Delegación en Huelva. Textos y documentación: J. Ma Cuenca López; diseño y maquetación: Virfran Publicidad. Huelva, 2000. Del mismo autor y también editado por la Consejería de Cultura: CD-ROM Tartessos: del mito a la realidad.

22. Ma del Carmen Valdés Sagüés: La difusión cultural en el museo: servicios destinados al gran público, p.p. 197. Gijón, 1999.

23. C. San Martín Montilla: "La difusión del patrimonio arqueológico desde el museo. Criterios de difusión". Boletín Informativo del IAPH, $n^{\circ}$ 7, p.p. 26-28. Sevilla, 1994

24. J. Ma Cuenca López y M. Martín Cáceres: “La excavación arqueológica: un centro de interpretación y difusión patrimonial (Una experiencia en el casco histórico de Huelva)". Aula - historia social n 4, otoño 1999, p. 88-94. Madrid, 1999.

25. Dirigidas ambas por D. Manuel Osuna Ruiz, las excavaciones se realizaron en el solar $n^{\circ} 7-13$ de la calle Méndez Nuñez y en el solar $n^{\circ}$ 15-17 de la calle Palos. Informes preliminares presentados a la Delegación Provincial de Cultura, Junta de Andalucía en 1998 y 1999 respectivamente (inéditos).

26. J. Prats, M. Tatjer y A. Villarrasa: "El proyecto Icaria: nuevas formas e instrumentos para conocer la ciudad". Iber, 24, p. 88-97. Barcelona, 2000. 